REVIEW ARTICLE

AFRICAN JOURNAL OF CLINICAL AND EXPERIMENTAL MICROBIOLOGY AJCEM/201176/21202

JANUARY2012 ISBN 1595-689X VOL 13(1)

AJCEM/201176/21202

-http://www.ajol.info/iournals/ajcem

AFR. J. CLN. EXPER. MICROBIOL 13(1): 35-40 http:/ / dx.doi.org/10.4314/ajcem/v13i1.3

\title{
CYTOMEGALOVIRUS IN IMMUNOSUPPRESSED PATIENTS: A SILENT AND POTENTIAL KILLER.
}

\author{
${ }^{1}$ Fowotade A. and ${ }^{1}$ Nwadike V.U. \\ Microbiology Department, University College Hospital, Ibadan, Nigeria. \\ Correspondence: Dr Fowotade Adeola, Medical Microbiology Department, University College Hospital, Ibadan, Nigeria. \\ GPO BOX 5553, Ilorin, Kwara State, Nigeria. E-mail- temilabike@yahoo.com TEL. No.- +234-705719038
}

\section{SUMMARY}

Cytomegalovirus (CMV) is a recognized cause of morbidity and mortality among immunocompromised individuals. This review will concentrate on understanding the pathogenesis, clinical manifestations and laboratory diagnostic options for CMV infection.

\section{KEY WORDS- REVIEW, CYTOMEGALOVIRUS, IMMUNOSUPPRESSED}

\section{INTRODUCTION}

Human Cytomegalovirus ( CMV) is an enveloped DNA virus, a potential killer or a lifelong silent killer (1). CMV infections are common and are usually asymptomatic however clinically ignificant infections are encountered frequently in pregnant women, neonates and immunocompromised patients (2). CMV is an important cause of orbidity and mortality among immunosuppressed patients. After a primary infection, which usually occurs during childhood, CMV reactivation occurs when the host immune system is compromised, either through infection such as, HIV immaturity(neonate) or through other iatrogenic means following organ transplantation, the virus is able to exert its full pathogenic potential (3)

$\mathrm{CMV}$ is one of the commonest viral opportunistic infection in persons with Acquired Immune Deficiency Syndrome (AIDS). Clinical disease due to CMV has been recognized in up to $5-25 \%$ of patients with AIDS (4). Prior to the advent of Highly Active Antiretroviral Therapy (HAART) for HIV infection, CMV retinitis was the most common cause of blindness in adults with AIDS (5). CMV is the most common cause of congenital malformation resulting from viral intrauterine infection in developed countries (6).

Virus associated leucopenia is common in solid organ transplant recipients, also seen are obliterative bronchiolitis in lung transplant, graft atherosclerosis after heart transplantation and Cytomegalovirus-related rejection of renal allografts $^{2}$. Clinical trials have shown that preventive approaches utilizing antiviral agents have lead to a reduction in the rates of CMV infection and disease and indirect sequelae associated with CMV. Currently, prophylaxis or periodic monitoring and antiviral therapy targeted towards patients with viral replication are routinely employed at many transplant centers.

The present article is meant to highlight the important features of the Cytomegaloviruses and also to increase the level of awareness on their potential to cause life threatening infections among the immunocompromised patients.

\section{STRUCTURE OF CMV}

Cytomegalovirus is a DNA virus belonging to the family Herpesviridae and the subfamily, Beta Herpesviridae which also includes the Roseolovirus and the Muromegalovirus. CMV is morphologically indistinguishable from other human Herpes viruses (7). Surface projections of envelope are distinct and spikes are dispersed evenly over the entire surface. The nucleocapsid is isometric, and surrounded by the tegument that consists of globular material which is frequently asymmetrically distributed and may be variable in amount (8). The nucleocapsid is sometimes penetrated by stain (although an intact envelope impermeable is to stain). Viral nucleocapsid is angular and has an icosahedral symmetry. There are 162 capsomeres per nucleocapsid, and capsomeres are hexagonal in cross section with a hole running half way down the long axis. The viral core consists of a fibrillar spool on which DNA is wrapped while the ends of the fibres are anchored to the underside of the capsid shell. Incomplete virus particles often present, and they represent capsids lacking the envelope.

CMV is inactivated by a number of physical and chemical treatments including; heat $\left(56.5^{\circ} \mathrm{C}\right.$ for 30 minutes), low $\mathrm{PH}$, ether, ultraviolet light and cycles of freezing and thawing8. CMV virions contain one molecule of linear double stranded DNA. Total genome length is $120,000-220,000$.Molecular virological techniques have been used to study variation among CMV strains. DNA strains have been shown to have similar but distinctive fragment 
migration patterns. Antigenic heterogeneity among CMV strains has been detected in cross neutralization and other serologic assays; however evidence for distinct serotypes is limited (9-11).

\section{EPIDEMIOLOGY OF CMV}

CMV is ubiquitous, being found universally throughout all geographic locations and socio economic groups, and infects between $50 \%$ and $85 \%$ of adults in the United States by 40 years of age (12). $\mathrm{CMV}$ infection is more widespread in developing countries and in areas of low socio economic condition (13). In the developing countries, very young children are often virtually universally CMV antibody positive (14). The early acquisition and high prevalence of CMV antibody has been ascribed to low socio economic conditions, poor hygiene, and overcrowding (14). However reports from studies carried out on the people of the New Guinea highland villages with primitive standards of hygiene and who often lived apart from childhood until marriage as well as studies carried out on people of the New Hebrides and Solomon island who lived in crowded population but are scrupulously clean, the prevalence of CMV infection was higher in the latter than the former group. It was therefore concluded that close personal contact, rather than poor hygiene was more important for the acquisition and spread of CMV. The vehicle of transmission of CMV has been shown to include; saliva, breast milk, intrauterine infection, urine, droplet infection, blood transfusion, organ transplantation, sexual intercourse and formites among others (6) .

\section{PATHOGENESIS OF CMV}

An understanding of the process of CMV viral replication will provide insights into its molecular mechanisms of infection and pathogenesis (15). Following infection, or contact with the virus, the CMV DNA enters the nucleus of the host cells and begins the process of replication and shedding, leading to the release of new virions (viral particles) into the blood and other body fluids. This replication cycle, takes approximately 24 hours, and consist of 3 phases; an immediate early phase (4 hours)-during which regulator proteins are made followed by an early phase (8 hours) - during which viral DNA polymers are made and a late phase (12hrs) - during which structural proteins and new progeny viral particles are assembled .

In an immunocompetent host, most of the virus is destroyed by CMV -specific cytotoxic T-cells, and the infectious process becomes asymptomatic. The presence of asymptomatic CMV infection is based on the detection of CMV in body fluids or on seroconversion from a negative to a positive status. The latter is defined as the appearance of IgM or a fourfold rise in the level of CMV specific IgG antibodies.

In immunocompromised patients who are not receiving prophylactic treatment against $\mathrm{CMV}$, symptomatic CMV infection; $\mathrm{CMV}$ disease and organ involvement may result (16). There are various mechanisms by which CMV disease may occur and these includes; direct cellular loss through viral infection, both of individual cells, and of larger foci because of propensity to spread, leading to coalescing cells. This close cell-cell interaction protects virus from antibody inactivation. Systemic hypoxic- Ischemic insult due to systemic hypotension and immunologic injury, involving antigen antibody complex deposition may also be involved in organs such as the kidney

Eventually, CMV attains a latent state and persistent infection within $\mathrm{T}$ - cells, endothelial cells and monocyte-derived macrophages ensues (16). Cell mediated immunity which is required for resolution of symptoms, also contributes to symptoms while the role of antibodies are limited Suppression of cell mediated immunity as seen in HIV infection allows recurrence of symptoms and can result in exacerbation of disease. The virus also has ability to induce immunosuppression in the body (9). The degree of morbidity induced by CMV is influenced by the degree of immunosuppression. In transplant recipients, there are two factors that influence the degree of morbidity due to CMV infection; the type and extent of immunosuppression, and the type of transplant. Morbidity is highest among bone marrow transplant (BMT) patients, and lowest among kidney transplant patients.

Multiple mechanisms of immune evasion for CMV could relate to the pathogenic role of the virus. Recently, the expression of immune evasion genes US3, US6, and US11 of CMV in the blood of solid organ transplant recipients has been investigated 11 .

\section{PATHOLOGY OF CMV}

CMV produces characteristic cytopathic changes on infected cells which appear large, rounded and contains ground glass appearing inclusion bodies in the cytoplasm. These infected cells are the hallmark of CMV infection and indicates the presence of $\mathrm{CMV}$ in a sample. The nuclear inclusion has the appearance of an owl's eyes because it is typically surrounded by a clear halo that extends to the nuclear membrane (17).

\section{CLINICAL MANIFESTATIONS OF CMV}

Following a first exposure to $\mathrm{CMV}$, the virus lies dormant in the body for life and can be reactivated. Usually a reactivated infection causes few or no symptoms. CMV disease may manifest in any of the under listed ways.

\section{A. Congenital infection:}

Congenital CMV infection is defined as the isolation of CMV from the saliva or urine of the neonate within 3 weeks of birth (18). The virus may also be transmitted from the mother to the infant in breast milk ${ }^{19}$. CMV is now the commonest cause of 
congenital infection and affects around $0.3 \%-1 \%$ of all live births ${ }^{20}$. A total of $5-10 \%$ of congenitally infected infants have symptoms at birth while fatal disease occurs in $20 \%$ of these infants (20). Ninety percent of the symptomatic survivors have long term sequelae while $15 \%$ of the asymptomatic survivors also have long term sequelae CMV is now the second commonest cause of mental retardation after Downs's syndrome and causes more cases of congenital damage than Rubella (21) .

Cytomegalic inclusion disease refers to any group of diseases caused by cytomegalovirus infection, and marked by characteristic inclusion bodies in enlarged infected cells. The classic disease is congenital, being acquired in utero from the mother and typically presents with intrauterine growth retardation, jaundice, hepatosplenomegaly, thrombocytopenia and encephalitis, with or without microcephaly. It is often difficult to differentiate, on clinical grounds between the several agents that may cause intrauterine infection. The severe thrombocytopenia, hepatitis, preumonitis and myocarditis attributed to the virus may be life threatening. CNS involvement may lead to seizures, focal neurological signs, and mental retardation. Unlike rubella, there is no evidence that CMV is teratogenic. Most of the damage is caused by destruction of target cells once they have been formed, and unlike rubella, the fetus can be damaged by infection during any stage of pregnancy. In $20 \%$ of cases $(1 \%$ of those who are congenitally infected), the infection is so severe that mortality occurs during infancy, while the rest are likely to sustain serious abnormalities for the rest of their lives. Brain damage is by far the commonest abnormality on follow up, and thus may manifest as microcephaly, mental retardation and seizures. The spectrum of brain damage varies from mild to severe. Optic atrophy, deafness, and blindness may also be present (22).

The effects of congenital CMV infection are as follows ; CNS abnormalities - microcephaly, mental retardation, spasticity, epilepsy, periventricular calcification, eye- choroidoretinits, and optic atrophy, ear - sensorineural deafness, liver hepatosplenomegaly and jaundice which is due to hepatitis., lung - pneumonia, heart - myocarditis, haematological - Thrombocytopenic purpura, haemolytic anaemia, neutopenia and lymphocytosis. Late sequelae include damage to the enamel forming organ of the teeth, resulting in yellow discoloration of the teeth and brittleness. This occurs in $40 \%$ of infants (22).

\section{B. PERINATAL INFECTION}

Despite the continued excretion of high titers of virus in the urine for many months, the vast majority of perinatally infected infants do not develop acute symptoms, although few cases of infantile pneumonitis have been reported $(21,23)$.
This appears to be an exceedingly rare event.

\section{POSTNATAL INFECTION}

The incubation period for CMV is thought to be 4-8 weeks. Primary CMV infection in the postnatal period is usually mild or asymptomatic. Occasionally, primary infection may be accompanied by the syndrome of infectious mononucleosis, with atypical lymphocytosis. This is similar to the syndrome produced by Epstein barr virus (EBV) except that lymphadenopathy is uncommon, and Paul-Bunnell test is negative. CMV- induced mononucleosis can be symptomatically indistinguishable from EBVinduced mononucleosis (24). Malaise, fever of up to $39.4^{\circ} \mathrm{C}$, chills, sore throat, headache, and fatigue can be the predominant features of both viruses. Many of the same clinical manifestations that are typical of EBV-induced mononucleosis (e.g. lymphadenopathy, splenomegaly, pharyngeal erythema) also can occur with CMV, although less frequently. Presentation of acute cytomegalovirus infection in an immunocompetent host may be in form of mononucleosis.

Patients with mononucleosis may present with nonspecific skin rashes such as; generalised maculopapular, urticarial, and scarlatiniform rashes. These rashes are not a direct cause of CMV proliferation within the skin, but are the result of an immunologic response to the virus. The classic hypersensitivity drug rash which is associated with ampicillin therapy given to patients with EBVinduced mononucleosis also can occur with CMVinduced mononucleosis. The post perfusion syndrome is essentially CMV mononucleosis acquired by blood transfusion (25). Sometimes the hepatitis picture predominates so that a diagnosis of non-non-B hepatitis is made.

\section{CMV INFECTION IN THE IMMUNOCOMPROMISED PATIENTS}

Primary CMV infection in immunocompromised individuals is far less likely to be asymptomatic. These patients develop spiking pyrexia, which resolves within a few days (25). Some may develop a viraemia with septicemia - like syndrome in the presence or absence of hepatitis. Pneumonitis may develop, which is associated with grave prognosis .The virus may disseminate to involve the retina, causing CMV retinitis. CMV retinitis is the commonest occular opportunistic infection, and the most common cause of visual loss in people with AIDS (23). CMV may disseminate to the gut, where it may cause an asymptomatic infection or ulceration or haemorrhage by the erosion of nearby blood vessels. In patients with CMV - induced immuno suppressive syndrome the patient becomes unable to deal with opportunistic infections such as Pseudomonas. AIDS patients may develop low grade encephalopathy and CMV adenitis. In addition, kaposi sarcoma has been associated with 
past CMV infection. CMV is by far the most common infection in bone marrow transplant recipients. Infection by this virus occurs in over onehalf of patients. The virus is an immunomodulator and CMV disease exacerbates an ongoing immunosupression in transplant recipient, thereby increasing the risk for bacterial and fungal infection such as Norcadia asteriodes, Mycoplasma, and Pneumocystis carini.

\section{LABORATORY DIAGNOSIS OF CMV INFECTION}

CMV should be suspected if a person has symptoms of infectious mononucleosis but has negative test results for mononucleosis and Epstein Barr virus, or negative heterophile antibody test and shows signs of hepatitis, but has negative test result for hepatitis A, B, and C (26).

\section{MICROSCOPY}

Electron microscopy - Virions in the urine of congenitally infected infants may be visualized by electron microscopy in up to $80 \%$ of cases $(27,28)$. The pseudoreplica method of electron microscopy can be used to detect the virus in urine and oral specimens of congenitally infected infants. Positive results can be obtained from almost all specimens that have infectivity titers of $>10^{4} / \mathrm{ml}$ of urine.

Tissue immunofluorescence - Infected tissue cells may be stained by specific anti CMV antibody. This is based on the principle that viral specific antibody conjugated to fluorescent labeled is allowed to react with the cells obtained from the clinical specimen. Preparations from bronchoalveolar lavage specimens can also be examined in this manner, and results of high sensitivity and specificity are possible. Cytomegalic inclusions can be recognized from biopsy materials by the typical 'owl's eyes appearance" (29).

\section{SEROLOGICAL DIAGNOSIS OF CMV INFECTION ENZYME LINKED IMMUNOSORBENT ASSAY}

A variety of tests are available for serologic diagnosis of CMV infection. The choice of method to be used depends on; factors such as the patient population, cost of test, turnaround time, equipment needs and ease of performance. Several commercial kits are available for detection of CMV IgG and IgM antibodies in body fluids. ELISA has replaced other traditional methods for detecting antibodies to CMV. The ELISA is based on the principle that Cytomegalovirus IgG and IgM specific antibodies are detected by addition of diluted patients 's sera to wells coated with purified CMV antigen. The IgG and IgM antibody, if present, binds to the antigen. An enzyme conjugate is added to bind the antigen-antibody complex, if present. A substrate to the enzyme is added, and a hydrolytic reaction between the enzyme and its substrate results in a change in the colour of the end product, whose intensity can be measured at $450 \mathrm{~nm}$ and is directly proportional to the amount of IgG specific antibody in the patient' s sera.

The main advantages of the ELISA are that; it is rapid, sensitive and specific. They are also useful in detection of CMV antibodies in urine. The limitation of ELISA is that they have low sensitivity when used to detect CMV antibodies in urine; this is because $\mathrm{CMV}$ is complexed to beta 2 microglobulin in the urine and may result in false positive results ${ }^{30}$.

\section{PASSIVE LATEX AGGLUTINATION TEST}

This provides a simple and rapid means of detecting antibodies to CMV in human sera and plasma. This method is highly sensitive and specific, and it may serve to determine the immune status of patient or blood donor populations. The procedure detects both IgG and IgM antibodies but does not differentiate between the two classes of immunoglobulins $(30,31)$.

\section{COMPLEMENT FIXATION}

The complement fixation (CF) test has been used for many years in clinical laboratories and is suitable for detecting rise in antibody titers. The CF test with glycine - extracted antigen is more sensitive for distinguishing sero-positive from sero-negative specimens.

\section{ANTIGEN DETECTION TESTS CMV ANTIGENEMIA TEST}

This test is based on the detection of pp 65, a structural protein expressed on the surface of infected polymorphonuclear leucocytes (32). The number of infected leucocytes present has been reported to correlate with the severity of infection. The main advantage of this test is that it is very rapid such that a result can be available within the same day.

\section{Detection of early antigen fluorescent foci} (DEAFF)

This is a method used for the early diagnosis of CMV infection. The specimen is inoculated into cell culture which is examined 24 hours later by immunofluorescence for expressed CMV encoded early proteins. The monoclonal antibodies must be able to cover most, if not all strains of CMV. Rapid culture methods other then the DEAFF tests are also available.

\section{VIRAL CULTURE}

Human CMV has been cultured in human cells only and previous claims that it could be grown in other animal cells is yet to be substantiated. Human fibroblast cells best support the growth of CMV and therefore can be used for diagnostic purposes. Acceptable fibroblast cultures include those prepared from human embryonic tissues or 
foreskins and serially passaged diploid human fetal lung strains such as W1-38, MRC-5, or IMR-90. The time of appearance and extent of cytopathic effect depends on the amount of virus present in specimens. CPE may develop by 24 hours and progress rapidly to involve most of the monolayer. More commonly foci of CPE, consisting of enlarged, rounded refractile cells appear during the first week and progresses slowly to surrounding cells.

\section{MOLECULAR TECHNIQUES \\ POLYMERASE CHAIN REACTION (PCR)}

The use of PCR in the diagnosis of CMV infection has been widely studied. The PCR is based on the use of thermostable DNA polymerase to extend oligonucleotide primers complimentary to the viral DNA genome target. Consecutive cycles of denaturation, annealing and extension results in an experimental accumulation of target DNA. PCR offers the advantages of being rapid and sensitive. However, its inherent sensitivity poses a problem since latent $\mathrm{CMV}$ genomes which are present in practically all sero-positive individuals, may be detected. In several studies, the sensitivity of the assay was increased by amplifying gene fragments from both the immediate early and late CMV genes or by using nested primers to a single gene fragment.

PCR has been used successfully to detect CMV DNA in a variety of clinical specimens from organ transplant recipients, patients with AIDS, and infants with congenital infection. The utility of PCR for the continued surveillance of immunocompromised patients and for evaluating the therapeutic efficacy of antiviral drugs has also been demonstrated.

\section{HYBRIDIZATION}

Molecular dot blot Hybridization techniques have been described for detection of the CMV genome in urine and peripheral blood leucocytes. Hybridization depends on the detection of a signal generated after the interaction of a labeled probe with the target nucleic acid. This occurs when the

\section{REFERENCES}

1. Hodinka, RL and Friedman, HM. Human Cytomegalovirus. In: Murray, PR, Baron, EJO, Pfaller, MA, Tenover, FC, Yolken, RH. Manual of Clinical Microbiology. 6th ed. ASM;2005; 556: 566569.

2. Brooks, GF, Caroll, KC, Butel, JS, Morse, SA. Herpes viruses In: Jawetz, Melnick \& Adelberg" s Medical Microbiology. 24th ed .2007; 428-451.

3. Emery, V.C. Investigation of CMV disease in immunocompromised patients. J Clin Pathol. 2001; 54: 84-88.

4. 4Murray, PR, Rosenthal, KS, Kobayashi, Pfaller, MA. Human Herpesviruses. sequence of nucleic probe is sufficiently similar to that of the target nucleic acid and a duplex is formed and held together by hydrogen bonds in nucleic pairing. Biotinylated or horseradish peroxidase labeled CMV specific DNA probe kits are commercially available. In situ hybridization has the advantage of being rapid and easy to read by light microscope.

\section{TREATMENT}

In the management of CMV disease, four different strategies can be utilized; antiviral therapy, prophylaxis, pre-emptive and suppressive treatment. Ganciclovir, a nucleoside analogue of guanine is a potent inhibitor of CMV replication in vitro. Valganciclovir, a prodrug of ganciclovir has also been found to be useful in treatment of CMV infection. The use of both drugs has been associated with myelosuppression which is often dose dependent. Foscarnet, a pyrophosphate analogue with in vitro activity against all human Herpes viruses as well as HIV has also been useful in treatment of CMV retinitis in AIDS patients. Nephrotoxicity and electrolyte imbalance are the most common toxicity associated with foscarnet. Foscarnet may be used as a second line therapy in CMV patients with ganciclovir resistance.

Oral ganciclovir has been licensed for CMV prophylaxis in patients with advanced AIDS. Routine prophylaxis however has not become standard in most HIV care settings, mainly due to the high cost of prophylaxis, potential toxicity and the inconvenience of taking 12 capsules per day.

\section{PREVENTION AND CONTROL}

Optimal prevention of CMV disease would be vaccination. However, until today there is no effective vaccine available. The Towne strain reduced the severity of disease without affecting the infection rate. Studies are currently going on to determine an alternative approach which is the use of subunit recombinant or DNA vaccines (32).

Medical Microbiology. 14th ed. Mosby Inc.2000; 475-498.

5. Vandkova, Z, Dvorak, P. Cytomegalovirus Infection in Immunocompetent and imunocompromised

individuals- a review. Curr Drug Targets Immune Endocr Metabol Disord.2001; 179187.

6. Stagno S. Reynolds DW., Pass RF and Alford C.A (1993): Breast milk and the risk of CMV infection. $N$ Engl J Med. 1993;302:1073-6.

7. Krench, U. Jung, M. and Hung, F.: The acquisition of Cytomegalovirus antibodies 
in a normal population: A serological study .J. Hyg. (Camb) 1997;63:798-89.

8. Tsaparas Y.F., Brigden M.L. Marthias R Thomas E. Proportion positive for Epstein barr virus, Cytomegalovirus, Toxoplasma, Human herpesvirus 6, Human Immunodeficiency Virus types $1 \& 2$ in heterophile negative patients with an absolute lymphocytosis. Arch. Pathol. Lab.Med .2003; 124:1324-30

9. Cicognac, Pollsky B . Cytomegalovirus infection in Bone marrow transplant patients . Infect Med.1993; 11:256-262.

10. Patel R. Syndman DR, Rubin RH., Ho, M Pescovitz $\mathrm{M}$, et al Serological findings in cytomegalovirus infection. Clin Infect Dis .2009; 61:1279-1289.

11. Patel, R., Snydman D.R Rubin R.H., Ho M, Pescovitz M. et al. Cytomegalovirus prophylaxis in solid organ transplant recipients. Clin. Dis.; 2009; 33.suppl 1:5327.

12. Leinikki, P., Heinonem, $\mathrm{K}$ and Pettay, O. Incidence of cytomegalovirus infections in early childhood Scand J. Inf. Dis.1996. 4:1-5.

13. Cabau, N., Coignard S, Labadie, M.D. et al Sero-epidemiology of cytomegalovirus infections during adolescence in urban communities. Arch. Dis. Child .54:286-90.

14. Bello, C.S.S. Cytomegalovirus infection in the Gambia M.D. Thesis. Ahmadu Bello University, Zaria, Nigeria. 1984

15. Bale JF, Zummerman B, Clud G.A, Pass F.F. Cytomegalovirus transmission in child care homes. Arch. Pediatr Adolescence Med. 1999;153:75-9.

16. Wingard, J.R, Piantadosis, S., Burn W.H. Pathogenesis of Cytomegalovirus infection after marrow transplantation. Infect Dis.1999; 153:478-88.

17. Euright, H., Haake, R., Weisdorf, D., et al Risk factors to Cytomegalovirus infection. J Infect Dis. 2001;55, 1339-46.

18. Meyers J. D ,Flournoy, N. Clinical syndromes cytomegalovirus infection after human marrow transplantation. I Infect Dis. $1996 ; \mathbf{1 5 3}, 478: 88$.

19. Goodwich, J.M., \& Bowden, R. Organ invovelment and changes in Cytomegalovirus infectious. Clin Infect Dis
$.1994 ; 19,287-98$.

20. Boeckh, M., Gooley, T.A., \& Bowden, R.A. Symptoms of Cytomegalovirus induced mononucleosis. J Infect Dis.2001;178, 11537.

21. Meyers, J.D., \& Dandliker, P.S (1998): Symptoms and signs of Cytomegalovirus infections. New Engl J Med .1998;318. 70-75.

22. Atkinson, K. \& Downs, D. (1995) Classical presenting features of infectious mononucleosis. Brit J Haematol . 1995; 79; $57-62$.

23. You, JC, Dimopoulos, M.A. Presentation and complication of cytomegalovirus in Bone marrow transplant patient. Euro J Haematol.2001; 47:371-6.

24. Goodrich, J.M. \& Mori, M. Opportunistic infections among. Bone marrow transplant recipients. New Engl J Med 2004;.325,16017.

25. Canpolat C, Culbert, S. Presenting features of cytomegalovirus infection in paediatric allogeneic bone marrow transplant recipients. J Med Virol.1997; 25: 179-188.

26. Greger B, Vallbracht A, Kurth J. Diagnostic tests in infectious mononucleosis. I Clin Microbiol 2003; 26, 2531-5.

27. Vander B.J.W, Speich R. Introduction to Cytomegalovirus infection and disease. Clin Dis. 2001; 33 Supp 1:S 32-7.

28. Hilt, D.C \& Buchhotz, D cytomegalovirus infection: diagnosis and management approaches. J Infect Dis.2001; 152:1172-81.

29. Bedayi PL, Risichella I.S. Strumia, R., Gilli P. et al, serologic \& Haematologic changes induced by acute cytomegalovirus infectious. J Infect Dis . 1997; 178; 1791-3.

30. Conti, D. J \& Freed B.M. Patterns of enzyme abnormities associated with Cytomegalovirus induced mononucleosis. Ann Int Med . 2006; 120; 375-6.

31. Kletzmayr, J. \& Kotzmann, H. Laboratory Diagnosis of Cytomegalovirus infection. Journal of the American society of virology 2006; 7; 325-30.

32. Einsele, H, Ehninger, G., Hebart, H. Cytomegalovirus pp 65 antigenaemia based diagnostic option. J Med Virol.2005; $14 ; 32-8.33$. 